\title{
Experimental Study on Tensile Creep of Coarse Recycled Aggregate Concrete
}

\author{
Tae-Seok Seo ${ }^{1)}$, and Moon-Sung Lee ${ }^{2), *} \mathbb{C}$
}

(Received March 2, 2015, Accepted July 23, 2015, Published online September 15, 2015)

\begin{abstract}
Previous studies have shown that the drying shrinkage of recycled aggregate concrete (RAC) is greater than that of natural aggregate concrete (NAC). Drying shrinkage is the fundamental reason for the cracking of concrete, and tensile creep caused by the restraint of drying shrinkage plays a significant role in the cracking because it can relieve the tensile stress and results in the delay of cracking occurrence. However, up till now, all research has been focusing on the compressive creep of RAC. Therefore, in this study, a uniaxial restrained shrinkage cracking test was executed to investigate the tensile creep properties caused by the restraint of drying shrinkage of RAC. The mechanical properties, such as compressive strength, tensile splitting strength, and Young's modulus of RAC were also investigated in this study. The results confirmed that the tensile creep of RAC caused by the restraint of shrinkage was about 20-30\% larger than that of NAC.
\end{abstract}

Keywords: recycled aggregate concrete, tensile creep, drying shrinkage, uniaxial restrained shrinkage cracking test.

\section{Introduction}

As vast amounts of waste materials produced during the demolition of concrete structures create environmental pollution, recycling of construction wastes offers a practical alternative to protect the environment (Enad et al. 2013). Therefore, the use of concrete containing demolished concrete material is an important issue for reducing the environmental load. Because aggregate takes up nearly $70 \%$ of concrete volume, the use of coarse recycled aggregate as a partial replacement for natural aggregate in the manufacturing of concrete has become a common practice. This concrete is called recycled aggregate concrete (RAC).

To encourage the usage of construction waste materials, many researchers have executed research on the mechanical characteristics of recycled aggregate (Soares et al. 2014a; Tavakoli and Soroushian 1996a; Valeria 2010) and the durability of recycled aggregate (Bravo et al. 2015; Ryou and Lee 2014; Sherif et al. 2015; Soares et al. 2014b). According to the studies of Domingo et al. (2009), Gholamreza et al. (2011), Rasiah et al. (2012), Tavakoli and Soroushian (1996b), and Xiao et al. (2014), the drying shrinkage of RAC is larger than that of NAC.

\footnotetext{
${ }^{1)}$ Hyundai Engineering and Construction Co., Ltd., Yongin 446-716, Korea.

${ }^{2)}$ Division of Architecture and Architectural Engineering, Hanyang University, Ansan 426-791, Korea.

*Corresponding Author; E-mail: moonlee@hanyang.ac.kr Copyright $($ The Author(s) 2015. This article is published with open access at Springerlink.com
}

The drying shrinkage is the fundamental reason for the cracking of concrete, and cracks occur when the tensile stress caused by the drying shrinkage exceed the tensile strength of the concrete (Tao et al. 2012). Tensile creep plays a significant role in cracking of concrete because it can relieve the tensile stress and results in the delay of cracking occurrence (Garas et al. 2009). However, up till now, all research has been focusing on the compressive creep of RAC (Domingo et al. 2009; Gholamreza et al. 2011; Xiao et al. 2014).

Therefore, in this study, a uniaxial restrained shrinkage cracking test was executed to investigate the tensile creep properties caused by the restraint of the drying shrinkage of RAC. In a uniaxial restrained shrinkage cracking test, specimens were designed to generate cracks caused by the restraint of drying shrinkage. These specimens were also used to investigate tensile stress, tensile creep, and cracking age. The mechanical properties of RAC, such as compressive strength, tensile splitting strength, and Young's modulus, were also investigated in this study.

\section{Experimental Program}

\subsection{Mixture Proportions and Materials}

Two different water-to-cement $(\mathrm{w} / \mathrm{c})$ ratios of 0.65 and 0.45 , and types of coarse aggregate were used to create four different concrete mixtures. In Korea, when recycled aggregates are used for concrete, the design strength of 21-27 MPa is recommended (KMCT, 2005). However, to encourage the usage of recycled aggregates, the design strength of concrete larger than $27 \mathrm{MPa}$ is included in this research. 
Table 1 Mixture proportions.

\begin{tabular}{|c|c|c|c|c|c|c|c|c|}
\hline \multirow[t]{2}{*}{ Specimen } & \multirow[t]{2}{*}{$\mathrm{w} / \mathrm{c}(\%)$} & \multirow[t]{2}{*}{$\mathrm{s} / \mathrm{a}(\%)$} & \multirow[t]{2}{*}{ Water $\left(\mathrm{kg} / \mathrm{m}^{3}\right)$} & \multicolumn{3}{|c|}{ Unit content $\left(\mathrm{kg} / \mathrm{m}^{3}\right)$} & \multicolumn{2}{|c|}{ Aggregate type } \\
\hline & & & & Cement & Fine aggregate & $\begin{array}{c}\text { Coarse } \\
\text { aggregate }\end{array}$ & Fine aggregate & $\begin{array}{c}\text { Coarse } \\
\text { aggregate }\end{array}$ \\
\hline $65-\mathrm{NC}$ & \multirow[t]{2}{*}{65} & \multirow[t]{2}{*}{47.0} & \multirow[t]{2}{*}{175} & \multirow[t]{2}{*}{270} & \multirow[t]{2}{*}{834} & 957 & \multirow[t]{4}{*}{$\mathrm{N}$} & $\mathrm{N}$ \\
\hline $65-\mathrm{RC}$ & & & & & & 942 & & $\mathrm{R}$ \\
\hline $45-\mathrm{NC}$ & \multirow[t]{2}{*}{45} & \multirow[t]{2}{*}{43.1} & \multirow[t]{2}{*}{175} & \multirow[t]{2}{*}{389} & \multirow[t]{2}{*}{724} & 972 & & $\mathrm{~N}$ \\
\hline $45-\mathrm{RC}$ & & & & & & 957 & & $\mathrm{R}$ \\
\hline
\end{tabular}

$w / c$ Water-to-cement ratio, $s / a$ fine aggregate proportion, $N$ natural, $R$ recycled

Table 2 Properties of aggregate.

\begin{tabular}{c|c|c|c}
\hline \multirow{2}{*}{ Specimens } & Recycled aggregate & \multicolumn{2}{|c}{ Natural aggregate } \\
\cline { 2 - 4 } & Coarse aggregate & Coarse aggregate & Fine aggregate \\
\hline \hline Density SSD $\left(\mathrm{g} / \mathrm{cm}^{3}\right)$ & 2.56 & 2.60 & 2.56 \\
\hline Dry density $\left(\mathrm{g} / \mathrm{cm}^{3}\right)$ & 2.50 & 2.58 & 2.51 \\
\hline Absorption ratio $(\%)$ & 2.50 & 1.07 & 2.25 \\
\hline Fineness modulus & 6.69 & 6.54 & 2.93 \\
\hline
\end{tabular}

Table 1 shows a list of the concrete mixture proportions. The reference mixture made of $100 \%$ natural aggregate is denoted by $\mathrm{NC}$ and the mixture made of $100 \%$ coarse recycled aggregate is denoted by $\mathrm{RC}$. The recycled coarse aggregate was added to the mixture after soaking in water, under conditions comparable to saturated surface-dry conditions. Ordinary Portland cement (specific surface area: $3300 \mathrm{~cm}^{2} / \mathrm{g}$, specific gravity: 3.16 ) was used, and superplasticizer was added to the mixture. The slump and air content of all concrete mixtures satisfied the target values (slump: $18 \pm 2.5 \mathrm{~cm}$, air content: $4.5 \pm 1.5 \%$ ). Table 2 shows the physical properties, such as density of saturated surface dry, dry density, absorption ratio, and fineness modulus, of coarse recycled aggregate and natural aggregate. According to Korean Standards (KMCT 2005), the absorption rate of coarse recycled aggregates should be smaller than $3 \%$, so the coarse recycled aggregates with the

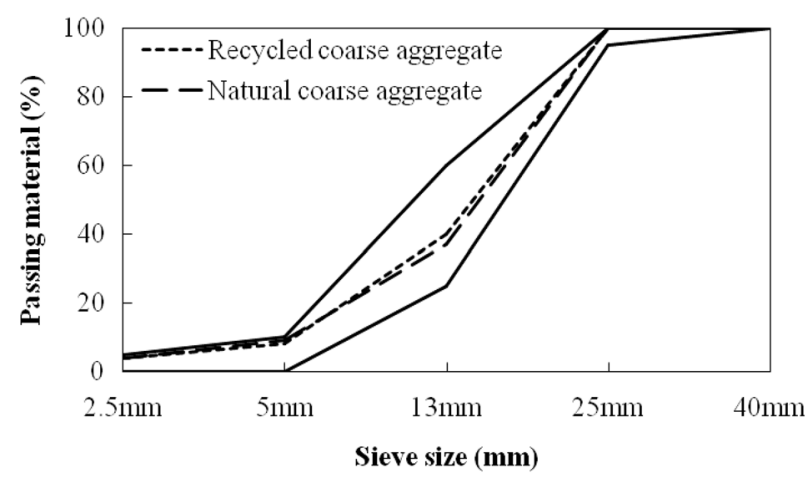

Fig. 1 Size distribution of coarse aggregate. absorption rate of $2.5 \%$ are used for the mixture. Figure 1 shows the size distribution of coarse aggregate.

\subsection{Shape and Kind of Specimens}

Figure 2 shows the shape of the uniaxial restrained shrinkage cracking specimen of JIS A 1151 (2002) that was used to investigate shrinkage cracking characteristics. In this specimen, the concrete is restrained by restraint steel $(100 \times 40 \times 40 \mathrm{~mm}$, thickness: $2.3 \mathrm{~mm}$, sectional area: $397 \mathrm{~mm}^{2}$ ) and is subjected to direct tensile stress due to the restraint of volume change caused by drying shrinkage. Cracking occurs when the tensile stress of steel is larger than that of the concrete. A prism with dimensions of $100 \times 100 \times 400 \mathrm{~mm}$ was made for studying the drying shrinkage. A cylinder with $100 \mathrm{~mm}$ diameter and $200 \mathrm{~mm}$ height was made for investigating the mechanical properties of concrete, such as, compressive strength, Young's modulus, and splitting tensile strength. Three specimens for each concrete mixture were produced for the uniaxial restrained shrinkage cracking test and these specimens were denoted by URSC $65-\mathrm{NC}-1$, URSC $65-\mathrm{NC}-2$, URSC 65-NC-3, URSC 65-RC-1, URSC 65-RC-2, URSC 65-RC-3, URSC 45-NC-1, URSC 45-NC-2, URSC 45-NC-3, URSC 45-RC1, URSC 45-RC-2, and URSC 45-RC-3, respectively.

\subsection{Testing Methods}

All specimens were demolded after a day, moist-cured for 7 days, and then exposed to air. They were stored in a controlled environment, temperature of $20 \pm 1{ }^{\circ} \mathrm{C}$ and relative humidity of $60 \pm 5 \%$. The uniaxial restrained shrinkage cracking tests and drying shrinkage tests were started after 7 days and conducted in accordance with JIS A 


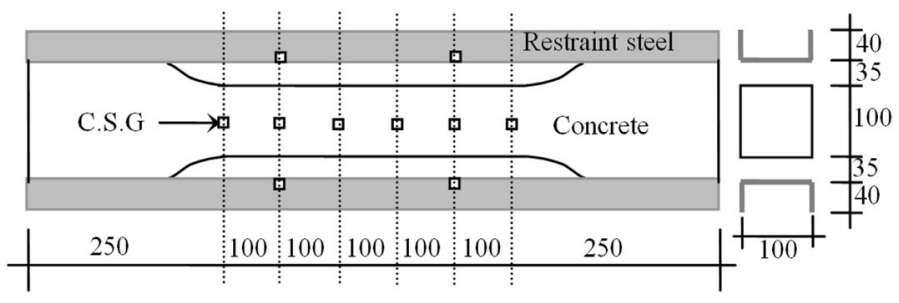

C.S.G: contact strain gauge

Fig. 2 Shape of uniaxial restrained shrinkage cracking specimen.

Table 3 Mechanical properties of concrete.

\begin{tabular}{c|c|c|c|c}
\hline Specimen & Items & 7 days & 14 days & 28 days \\
\hline \hline \multirow{5}{*}{$65-\mathrm{NC}$} & $f_{c}(\mathrm{MPa})$ & 26.3 & 32.5 & 2.5 \\
\cline { 2 - 5 } & $f_{s t}(\mathrm{MPa})$ & 2.3 & 2.6 & 27.7 \\
\cline { 2 - 5 } & $E_{c}(\mathrm{GPa})$ & 22.9 & 25.5 & 30.3 \\
\cline { 2 - 5 } & $f_{c}(\mathrm{MPa})$ & 22.0 & 2.3 & 2.6 \\
\cline { 2 - 5 } & $f_{s t}(\mathrm{MPa})$ & 2.1 & 23.9 & 24.6 \\
\hline \multirow{5}{*}{ 65-RC } & $E_{c}(\mathrm{GPa})$ & 20.9 & 46.1 & 49.9 \\
\cline { 2 - 5 } & $f_{c}(\mathrm{MPa})$ & 39.4 & 3.1 & 3.4 \\
\cline { 2 - 5 } & $f_{s t}(\mathrm{MPa})$ & 2.8 & 30.3 & 31.5 \\
\hline \multirow{5}{*}{$45-\mathrm{NC}$} & $E_{c}(\mathrm{GPa})$ & 28.0 & 38.7 & 40.0 \\
\cline { 2 - 5 } & $f_{c}(\mathrm{MPa})$ & 33.5 & 2.8 & 3.1 \\
\cline { 2 - 5 } & $f_{s t}(\mathrm{MPa})$ & 2.6 & 27.8 & 28.3 \\
\hline
\end{tabular}

$f_{c}$ Compressive strength, $f_{s t}$ splitting tensile strength, $E_{c}$ Young's modulus.

1129 (2001) and JIS A 1151 (2002), respectively. A contact strain gauge (CSG) with a precision of $1 / 1000$ was used to measure the strain. Compressive strength and splitting tensile strength tests were conducted in accordance with JIS A 1108 (1999a) and JIS A 1113 (1999b), respectively.

\section{Results and Analysis}

\subsection{Mechanical Properties of Concrete}

Table 3 shows the mechanical properties, such as compressive strength, tensile splitting strength, and Young's modulus, of the concrete specimens with 7, 14 and 28 days of curing. Each test results were shown in an average of the results of three specimens. The compressive strength and splitting tensile strength of $65-\mathrm{RC}$ specimens containing coarse recycled aggregate at 28 days showed a decrease of about $20 \%$ and about $10 \%$, respectively, compared to those of 65-NC specimens containing $100 \%$ natural aggregate. The Young's modulus of 65-RC specimens at 28 days was about $10 \%$ smaller than that of $65-\mathrm{NC}$ specimens. Similar results were also observed for 45-RC and 45-NC specimens at 28 days. Low density and high water absorption and porosity, mainly caused by the heterogeneous nature of recycled aggregate, can lead to low quality concrete (Khaleel and Kypros 2013).

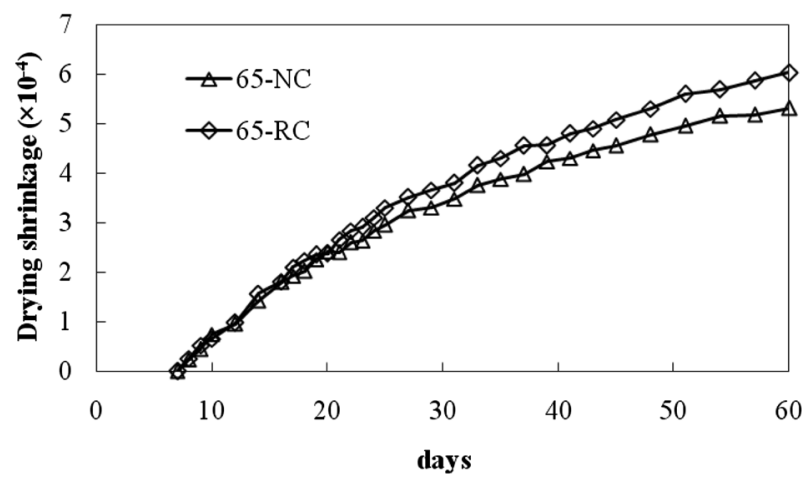

(a) $\mathrm{w} / \mathrm{c}=65 \%$

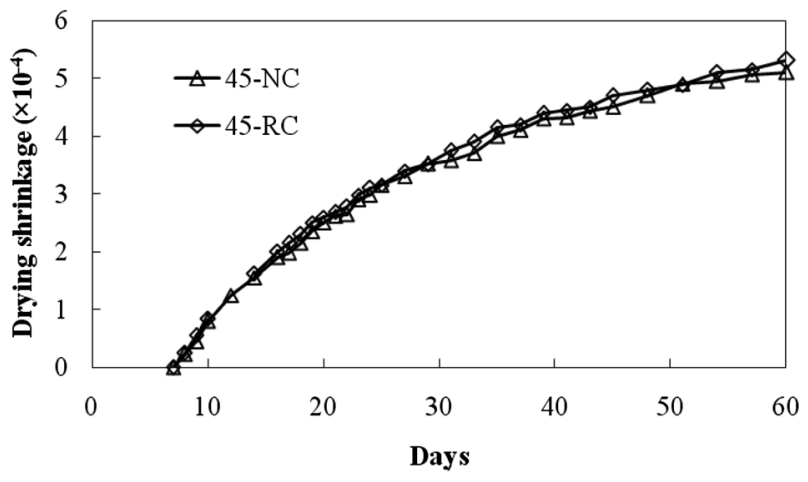

(b) $\mathrm{w} / \mathrm{c}=45 \%$

Fig. 3 Drying shrinkage. 


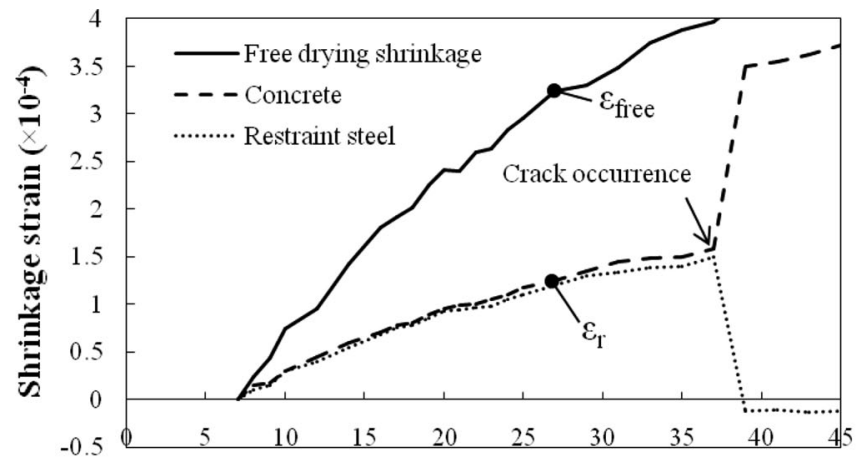

Days

(a) $65-\mathrm{NC}$

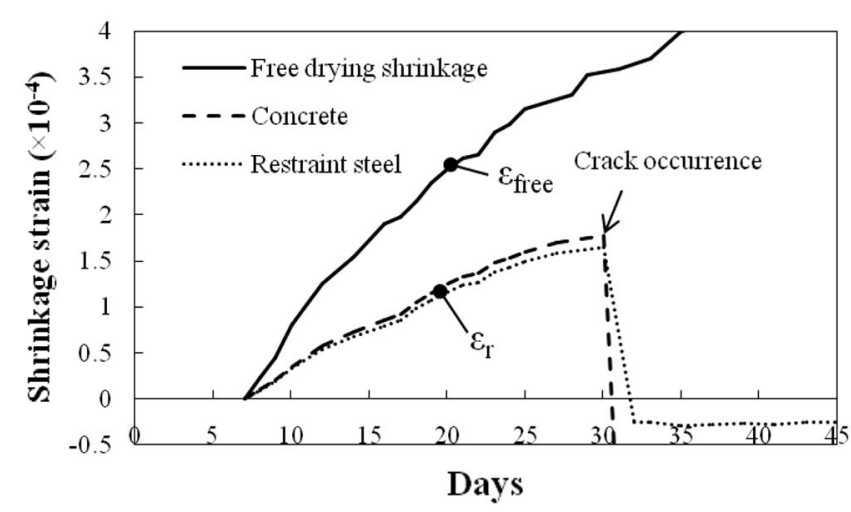

(c) $45-\mathrm{NC}$

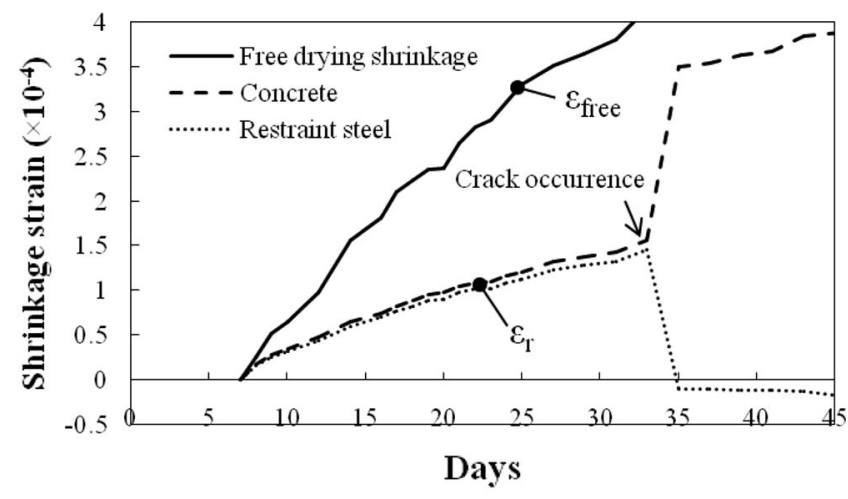

(b) $65-\mathrm{RC}$

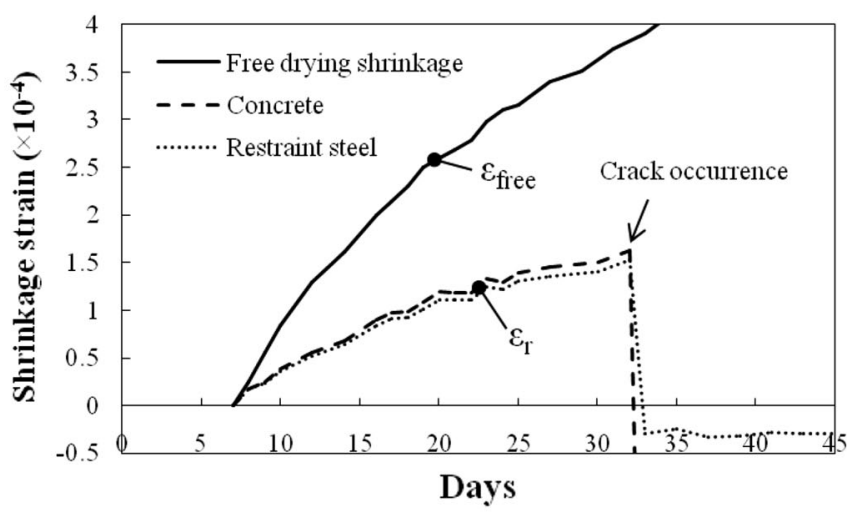

(d) 45-RC

Fig. 4 Shrinkage behavior of uniaxial restrained shrinkage cracking specimens.

Table 4 Cracking age.

\begin{tabular}{c|c|c}
\hline Specimen & Cracking age & Average value (cracking age) \\
\hline \hline URSC 65-NC-1 & 37 days & \\
\hline URSC 65-NC-2 & 35 days & \\
\hline URSC 65-NC-3 & 31 days \\
\hline URSC 65-RC-1 & 33 days & 32.3 days \\
\hline URSC 65-RC-2 & 31 days & \\
\hline URSC 65-RC-3 & 33 days & \\
\hline URSC 45-NC-1 & 30 days & \\
\hline URSC 45-NC-2 & 29 days & \\
\hline URSC 45-NC-3 & 31 days & \\
\hline URSC 45-RC-1 & 32 days & \\
\hline URSC 45-RC-2 & 29 days & \\
\hline URSC 45-RC-3 & 30 days & \\
\hline
\end{tabular}

\subsection{Drying Shrinkage}

Figure 3 shows the free drying shrinkage strain $\varepsilon_{\text {free }}$ across the specimens. The results of each drying shrinkage test were shown in an average of the results of three specimens for each concrete mixture. In $\mathrm{w} / \mathrm{c}=65 \%$ concrete, the drying shrinkage of RC specimens at 60 days was about
$20 \%$ larger than that of $\mathrm{NC}$ specimens, and in $\mathrm{w} / \mathrm{c}=45 \%$ concrete, the drying shrinkages of NC specimens and $\mathrm{RC}$ specimens were almost the same. In AIJ (2003), to ensure the quality of drying shrinkage the maximum shrinkage should be smaller than $800 \mu \varepsilon$. All the specimens tested satisfied this quality control regulation. 


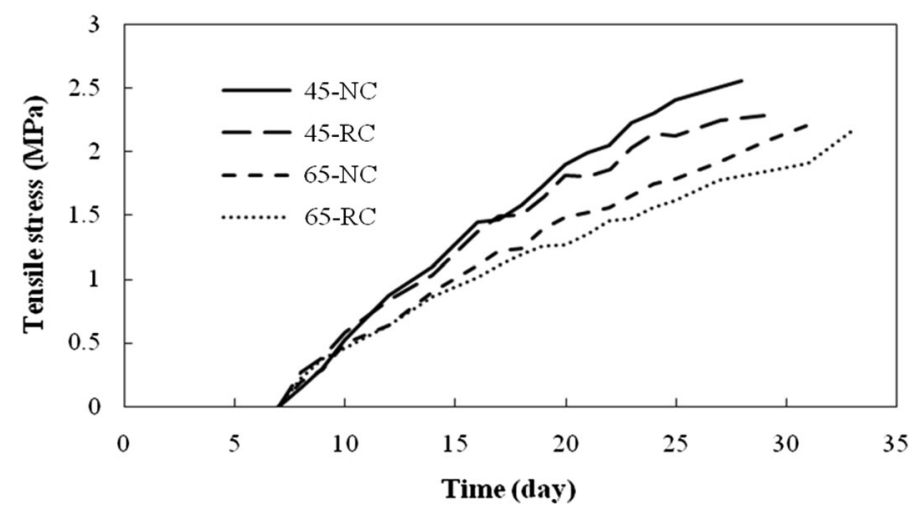

Fig. 5 Behavior of tensile stress.

\subsection{Uniaxial Restrained Shrinkage Cracking Test}

\subsubsection{Cracking Age}

Figure 4 shows the restrained shrinkage strain, $\varepsilon_{r}$, of the uniaxial restrained shrinkage cracking specimens (the first specimen out of the three specimens for each concrete mixture, URSC 65-NC-1, URSC 65-RC-1, URSC 45-NC-1, and URSC $45-\mathrm{RC}-1$ ) and the free drying shrinkage, $\varepsilon_{\text {free }}$ (see Fig. 3), of concrete. The restrained shrinkage strains, $\varepsilon_{r}$, of concrete and restraint steel were almost identical. The cracking age of each specimen was determined based on the point where the sudden change in restrained shrinkage occurred. Table 4 presents the cracking age. Within the specimens with the same $\mathrm{w} / \mathrm{c}$ ratio, there was no significant difference in cracking age between NC specimens and RC specimens.

\subsubsection{Histories of Tensile Stress}

The tensile stress of concrete was obtained using Eq. (1) based on the force equilibrium between the restraint steel and concrete. Figure 5 shows the behavior of tensile stress of concrete from the uniaxial restrained shrinkage cracking test. These tensile stress results were shown in an average of the results of three specimens for each concrete mixture. For example, the results of $65-\mathrm{NC}$ were an average of the results of the specimens URSC $65-\mathrm{NC}-1$, URSC $65-\mathrm{NC}-2$ and URSC 65-NC-3. The tensile stress behaviors between these three results were similar to each other. The results of the specimens with other concrete mixtures, 65-RC, 45-NC, and
45-RC, were also shown in Fig. 5. The tensile stress of all concrete mixtures almost linearly increased with time. Regardless of the w/c ratio, the tensile stresses of $\mathrm{RC}$ specimens showed about $10 \%$ reduction with time compared to those of NC specimens. Behavior like this was observed since the stress relaxation of RAC is expected to be larger than that of NAC.

$$
\sigma_{t}=\frac{E_{s} \cdot \varepsilon_{r} \cdot A_{s}}{A_{c}}
$$

where $E_{s}$ is the elastic modulus of restraint steel, $\varepsilon_{r}$ is the restrained shrinkage strain, $A_{s}$ is the sectional area of the restraint steel, and $A_{c}$ is the sectional area of concrete.

\subsubsection{Histories of Tensile Creep}

Figure 6 shows the conceptual diagram of tensile strain of concrete of the restrained shrinkage specimen. Since the restrained tensile strain, $\varepsilon_{t}$, is defined as the sum of the elastic strain, $\varepsilon_{e}$, and the tensile creep strain, $\varepsilon_{c}$, according to previous studies (Kanda 2005; Shima and Ichikawa 2009), the tensile creep strain can be obtained from Eq. (2). The elastic strain, $\varepsilon_{e}$, for Eq. (2) was obtained by using the tensile stress of concrete from Eq. (1) and the Young's modulus from the approximate regression equation shown in Fig. 7 based on measured Young's modulus shown in Table 3. Figure 8 shows the behavior of tensile creep, found from Eq. (2), of concrete occurred in the restrained shrinkage specimens. The tensile creep of specimens with $\mathrm{w} / \mathrm{c}=65 \%$ was larger than

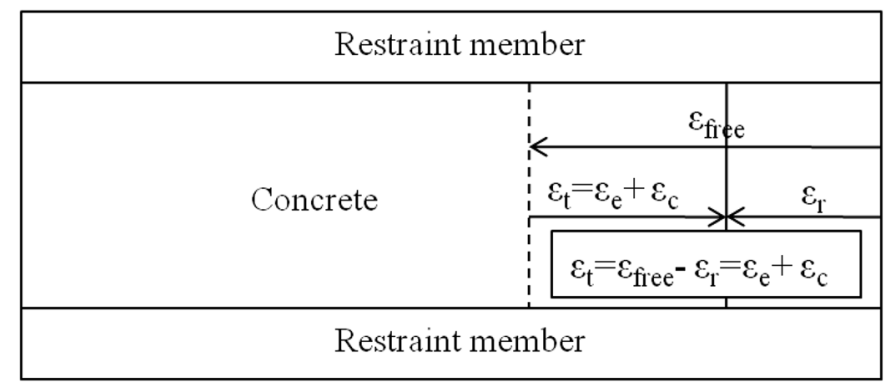

$\varepsilon_{\mathrm{c}}:$ tensile creep strain, $\varepsilon_{\text {free }}$ : free drying shrinkage, $\varepsilon_{\mathrm{e}}:$ elastic strain $\varepsilon_{\mathrm{r}}$ : restrained shrinkage strain, $\varepsilon_{\mathrm{t}}:$ restrained tensile strain

Fig. 6 Conceptual diagram of restrained tensile strain. 


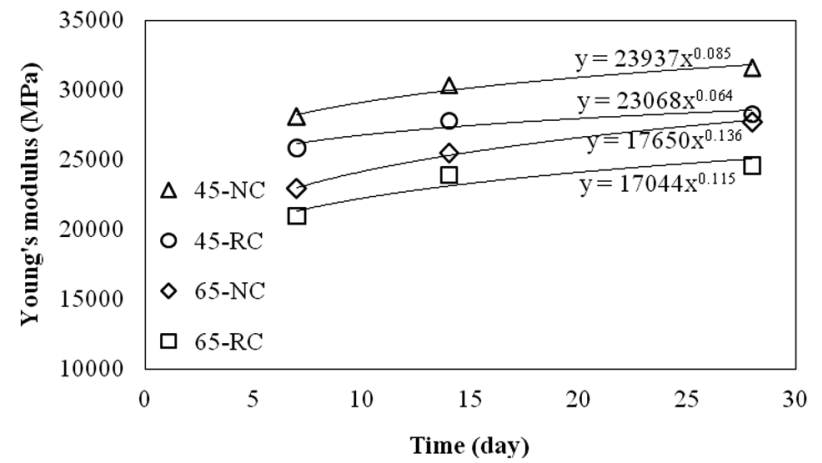

Fig. 7 Concrete Young's modulus.

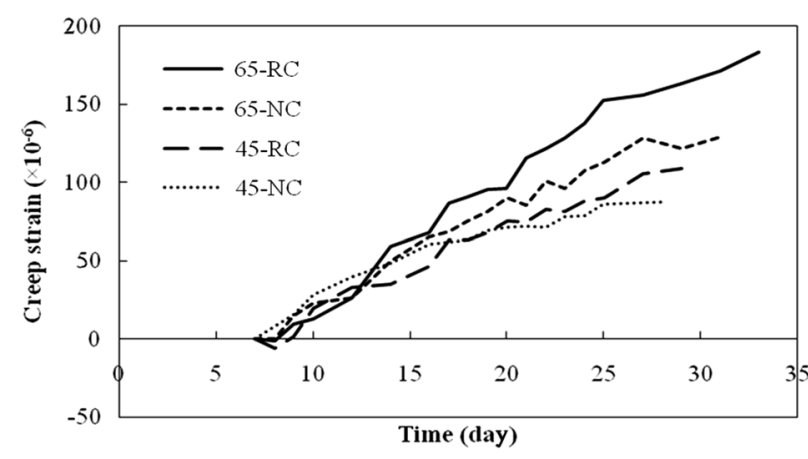

Fig. 8 Tensile creep strain.

that of specimens with $\mathrm{w} / \mathrm{c}=45 \%$. For specimens with $\mathrm{w} /$ $\mathrm{c}=65 \%$, the tensile creep of concrete of $\mathrm{RC}$ was about $30 \%$ larger than that of NC. For specimens with w/ $\mathrm{c}=45 \%$, after 17 days, the tensile creep of concrete of RC was about $20 \%$ larger than that of NC. According to previous studies (Domingo et al. 2009; Gholamreza et al. 2011; Xiao et al. 2014), for compressive creep, the creep deformation of RAC is $20-60 \%$ larger than that of NAC. Based on the results of this study, for tensile creep due to restraint of shrinkage, the creep deformation of RAC is $20-30 \%$ larger than that of NAC. Although the tensile strength of the concrete with recycled aggregates is smaller than that of the concrete with natural aggregates, the cracking age was similar to each other, since the stress relaxation of the concrete with recycled aggregates caused by tensile creep is larger than that of the concrete with natural aggregates.

$$
\varepsilon_{c}=\varepsilon_{\text {free }}-\varepsilon_{e}-\varepsilon_{r}
$$

where $\varepsilon_{c}$ is the tensile creep strain, $\varepsilon_{\text {free }}$ is the free drying shrinkage, $\varepsilon_{e}$ is the elastic strain and $\varepsilon_{r}$ is the restrained shrinkage strain.

\section{Conclusion}

In this study, a uniaxial restrained shrinkage cracking test was carried out to investigate the tensile creep properties caused by the restraint of drying shrinkage of RAC. The mechanical properties of RAC, such as compressive strength, tensile splitting strength, and Young's modulus, were also investigated. All the conclusions drawn from this research are limited to coarse recycled aggregates with the absorption rate of $2.5 \%$ and should be used with caution due to the limited number of mixes tested. The study results are summarized as follows:

(1) For both $\mathrm{w} / \mathrm{c}=65 \%$ and $\mathrm{w} / \mathrm{c}=45 \%$ concrete, the compressive strength and splitting tensile strength of $\mathrm{RC}$ specimens containing coarse recycled aggregate at 28 days showed a decrease of about $20 \%$ and about $10 \%$, respectively, compared to those of NC specimens containing $100 \%$ natural aggregate at 28 days.

(2) In $\mathrm{w} / \mathrm{c}=65 \%$ concrete, the drying shrinkage at 60 days of RC specimens was about $20 \%$ larger than that of $\mathrm{NC}$ specimens. In $\mathrm{w} / \mathrm{c}=45 \%$ concrete, the drying shrinkages of NC specimens and RC specimens were almost the same.

(3) The tensile stress of all concrete mixtures almost linearly increased with time, and the tensile stress of $\mathrm{RC}$ specimens showed about $10 \%$ reduction compared to that of $\mathrm{NC}$ specimens.

(4) According to previous studies, for compressive creep, creep deformation of RAC is $20-60 \%$ larger than that of NAC. Based on the results of this study, for tensile creep due to restraint of shrinkage, the creep deformation of RAC is $20-30 \%$ larger than that of NAC.

(5) For cracking age, if the specimens have the same w/c ratio, the difference between $\mathrm{NC}$ specimens and $\mathrm{RC}$ specimens was very small. Although the tensile strength of the concrete with recycled aggregates is smaller than that of the concrete with natural aggregates, the cracking age was similar to each other, since the stress relaxation of the concrete with recycled aggregates caused by tensile creep is larger than that of the concrete with natural aggregates.

\section{Open Access}

This article is distributed under the terms of the Creative Commons Attribution 4.0 International License (http://creativecommons.org/licenses/by/4.0/), which permits unrestricted use, distribution, and reproduction in any medium, provided you give appropriate credit to the original author(s) and the source, provide a link to the Creative Commons license, and indicate if changes were made.

\section{References}

AIJ. (2003). Recommendations for practice of crack control in reinforced concrete structures (design and construction), Architectural Institute of Japan (in Japanese).

Bravo, M., Brito, J., Pontes, J., \& Evangelista, L. (2015). Durability performance of concrete with recycled aggregates from construction and demolition waste plants. Construction and Building Materials, 77, 357-369. 
Domingo, A., Lázaro, C., López, F., Serrano, M., Serna, P., \& Castaño, J. (2009). Creep and shrinkage of recycled aggregate concrete. Construction and Building Materials, 23(7), 2545-2553.

Enad, M., Ahmad, I., Hassan, E., \& Varun, C. P. (2013). Self consolidating concrete incorporating high volume of fly ash, slag, and recycled asphalt pavement. International Journal of Concrete Structures and Materials, 7(2), $155-163$.

Garas, V., Kahn, L., \& Kurtis, K. (2009). Short-term tensile creep and shrinkage of ultra high performance concrete. Cement and Concrete Composite, 30(3), 147-152.

Gholamreza, F., Ghani, R., Burkan, I., Abdelgadir, A., Benoit, F., \& Simon, F. (2011). Creep and drying shrinkage characteristics of concrete produced with coarse recycled concrete aggregate. Cement \& Concrete Composites, 33(10), 1026-1037.

JCI Committee. (1999a). JIS A 1108: Method of test for compressive strength of concrete. Tokyo, Japan: Japanese Standards Association (in Japanese).

JCI Committee. (1999b). JIS A 1113: Method of test for splitting tensile strength of concrete. Tokyo, Japan: Japanese Standards Association (in Japanese).

JCI Committee. (2001). JIS A 1129: Method of test for length change of mortar and concrete. Tokyo, Japan: Japanese Standards Association (in Japanese).

JCI Committee. (2002). JIS A 1151: Method of test for drying shrinkage cracking of restrained concrete. Tokyo, Japan: Japanese Standards Association (in Japanese).

Kanda, T. (2005). Quantitative evaluation of shrinkage cracking initiation. Concrete Journal of the Japan Concrete Institute, 43(5), 60-66 (in Japanese).

Khaleel, H., \& Kypros, P. (2013). Strength prediction model and methods for improving recycled aggregate concrete. Construction and Building Materials, 49, 688-701.

KMCT. (2005). Quality standard of recycled aggregate, Korea Ministry of Construction and Transportation (in Korean).
Rasiah, S., Neo, D. H. W., \& Lai, J. W. E. (2012). Mix design for recycled aggregate concrete. International Journal of Concrete Structures and Materials, 6(4), 239-246.

Ryou, I. S., \& Lee, Y. S. (2014). Characterization of recycled coarse aggregate (RCA) via a surface coating method. International Journal of Concrete Structures and Materials, $8(2), 165-172$.

Sherif, Y., Kareem, H., Anaam, A., Amani, Z., \& Hiba, I. (2015). Strength and durability evaluation of recycled aggregate concrete. International Journal of Concrete Structures and Materials, 9(2), 219-239.

Shima, H., \& Ichikawa, D. (2009). Measurement of tensile creep of concrete under restrained drying shrinkage conditions using ring specimens. Japan Society of Civil Engineering, 65(4), 477-489 (in Japanese).

Soares, D., Brito, J., Ferreira, J., \& Pacheco, J. (2014a). In situ materials characterization of full-scale recycled aggregates concrete structures. Construction and Building Materials, $71,237-245$.

Soares, D., Brito, J., Ferreira, J., \& Pacheco, J. (2014b). Use of coarse recycled aggregates from precast concrete rejects: mechanical and durability performance. Construction and Building Materials, 71, 263-272.

Tao, J., Chen, C., Zhuang, Y., \& Lin, X. (2012). Effect of degree of ceramsite prewetting on the cracking behavior of LWAC. Magazine of Concrete Research, 61(1), 1-9.

Tavakoli, M., \& Soroushian, P. (1996a). Strength of recycled aggregate concrete made using field-demolished concrete as aggregate. ACI Materials Journal, 93(2), 178-181.

Tavakoli, M., \& Soroushian, P. (1996b). Drying shrinkage behavior of recycled aggregate concrete. Concrete International, 18(11), 58-61.

Valeria, C. (2010). Mechanical and elastic behavior of concretes made of recycled-concrete coarse aggregates. Construction and Building Materials, 24(9), 1616-1620.

Xiao, J., Li, L., Tam, V. W. Y., \& Li, H. (2014). The state of the art regarding the long-term properties of recycled aggregate concrete. Structural Concrete, 15(1), 3-12. 